\title{
"ELES SEMPRE TÊM UM POUQUINHO DE MÁGICA": O QUE DIZEM JOVENS LEITORES SOBRE O GÊNERO LITERÁRIO CONTOS DE FADAS
}

\author{
Paulo Ailton Ferreira da Rosa Junior \\ Mestre em Educação pela Universidade Federal de Pelotas (UFPel) \\ juuniorferreira@yahoo.com.br
}

\section{RESUMO}

Este artigo resulta de parte de uma pesquisa de mestrado em Educação, realizada no âmbito do grupo História da Alfabetização, Leitura, Escrita e dos Livros Escolares (HISALES), vinculado ao Programa de Pós-graduação em Educação (PPGE), da Universidade Federal de Pelotas (UFPEL). Ele tem por objetivo analisar as declarações de sete jovens leitores reunidos em um grupo de discussão sobre contos de fadas, a fim de estabelecer aproximações e distanciamentos das suas concepções acerca desse gênero literário em relação ao que estudiosos do assunto postulam sobre ele. Pautam a discussão autores como Corso e Corso (2006), Coelho (2000) e Bettelheim (2014), bem como Gatti (2012), cuja ideia de grupo focal nos serviu como aporte metodológico.

Palavras-chave: Contos de fadas, jovens leitores, gênero literário.

\section{ABSTRACT}

This article is part of a master's research in Education carried out within the group History of Literacy, Reading, Writing and School Books (HISALES), linked to the Postgraduate Program in Education (PPGE), of the Federal University of Pelotas (UFPEL). It aims to analyze the statements of seven young readers gathered in a discussion group on fairy tales in order to establish approximations and distances from their conceptions about this literary genre in relation to what scholars of the subject postulate about it. Authors like Corso and Corso (2006), Coelho (2000) and Bettelheim (2014) rule the discussion, as well as Gatti (2012), whose idea of focus group served as a methodological contribution.

Keywords: Fairy tales, young readers, literary genre. 


\section{Introdução}

Os contos de fadas surgem-nos, tradicionalmente, ainda na infância, seja através da prática da contação de histórias, que remonta aos primórdios de nossos passeios pelos bosques da imaginação, ou das animações dos estúdios Walt Disney, que vêm encantando gerações desde meados do início do século XX. Para além, no raiar desse novo século vêm sendo possível perceber um crescente interesse de outras faixas etárias por essas histórias, visto a popularidade alcançada por produções televisivas, cinematográficas e de livros juvenis que vêm recontando essas narrativas seculares.

Nanda (2014, p. 246) afirma que o termo "conto de fadas" foi usado pioneiramente em 1697, quando Marie Catherine d'Aulnoy publicou sua primeira coletânea de contos. Levado para a língua inglesa por volta de 1750 (traduzido como fairy tale), espalhou-se pelos demais idiomas do continente europeu (conte de fée, na França e Märchen, na Alemanha, por exemplo) como determinado tipo de história em que se celebra coisas como a beleza, a generosidade e o amor verdadeiro. Entretanto, essa concepção, se confrontada com as referidas produções atuais que revisitam o gênero com tons de terror e mistério, ou mesmo com as traduções dos textos primevos publicados entre os séculos XVIII e XIX, parece não se sustentar.

Um estudioso que ofereceu uma definição que parece traduzir bem essa hesitação sobre o gênero dos contos de fadas foi Haase (2008), quando postulou que "para alguns, o termo denota uma forma narrativa específica cujas características são facilmente identificáveis, mas para outros, ele sugere não um gênero singular, mas um guarda chuva sob o qual uma variedade de formas podem ser agrupadas" (HAASE, 2008, p. 322 tradução do autor). 
Para aclarar essa questão reunimos, então, um grupo de sete jovens leitores com idades entre 13 e 17 anos (identificados no texto de J1 a J7) para discutir o tema dos contos de fadas em uma metodologia de pesquisa inspirada na do grupo focal, segundo Gatti (2012), que o postula como "um conjunto de pessoas selecionadas e reunidas por pesquisadores para discutir e comentar um tema, que é objeto de pesquisa, a partir de sua experiência pessoal” (POWELL; SINGLE apud GATTI, 2012, p. 7). Dessa forma, o objetivo deste artigo é, a partir do material oriundo desses encontros - excertos previamente selecionados das gravações em áudio transcritas em texto - estabelecer aproximações e afastamentos das concepções oferecidas pelo grupo de discussão em torno de características que definiriam o gênero conto de fadas, em relação com as discussões teóricas que permeiam esse objeto de estudo. Para tal, foram identificados consensos e contrassensos, entre eles, demonstrados a seguir, a fim de postular uma releitura possível do conceito de conto de fadas.

\section{Discussão}

O primeiro excerto selecionado apura que, "Se é conto de fadas... bom... tem dragão, elfos... tem fadas" (J3). Corso e Corso (2006, p. 27), entretanto, alertam que contos de fadas não precisam apresentar fadas dentre os seus personagens e, de fato, Sale $(1977$, p. 372$)$ conta que muito poucas dessas histórias nos introduzem a fadas ou elfos ou duendes ou criaturas similares. A referência à fada, ambos concordam, é uma alusão ao caráter extraordinário dessas histórias.

Consequentemente, a característica dos contos de fadas mais frequentemente apontada pelo grupo é a constância desse caráter, que eles chamaram de "magia" ou 
"mágica", em falas como as transcritas a seguir: "eu acho que ele [o conto de fadas] é bem fora da realidade da gente, tipo numa realidade mágica" (J2), "[conto de fadas] tem magia" (J6), "[conto de fadas] tem uma certa magia" (J3), "[conto de fadas] tem bastante magia" (J7), "eles [os contos de fadas] sempre têm um pouquinho de mágica" (J4). Estamos lidando aqui, ao que parece, com o que chamamos de "elemento maravilhoso", onipresente nessas narrativas, determinado estado extraordinário das coisas que não é o do nosso cotidiano mundano. Sobre ele, Coelho $(2000$, p. 172$)$ conta que:

\begin{abstract}
Desse maravilhoso nasceram personagens que possuem poderes sobrenaturais; deslocam-se contrariando as leis da gravidade; sofrem metamorfoses contínuas; defrontam-se com as forças do Bem e do Mal, personificadas; sofrem profecias que se cumprem; são beneficiadas com milagres; assistem a fenômenos que desafiam as leis da lógica, etc. (COELHO, 2000, p. 172).
\end{abstract}

Os contos de fadas, assim, define Bastos (1994, p. 118), giram em torno do que nunca poderá existir no reino da experiência empírica, como evidenciam as falas transcritas a seguir: "Eu acho que conto de fadas é, tipo, histórias com o que não tem, como, por exemplo, gato falar... um coelho chamar ela... essas coisas assim" (J1); "sempre tem uma maldição, né?" (J4); "tem a fada que realiza desejos" (J3); "princesas que dormem pra sempre" (J7). Cria-se, desse modo, uma "crença secundária" por parte do leitor relativa ao universo ficcional, que é exterior ao espaço-tempo normal e contínuo de todos os dias. As costumeiras expressões que abrem essas narrativas, "Era uma vez...", "Há muito, muito tempo...", "Em um reino muito distante...", são como um contrato firmado de chofre para que o leitor ou ouvinte suspenda-se do mundo natural. 
Portanto, o grupo concordou que o que o conto de fadas faz, essencialmente, é narrar acontecimentos que se distanciam dos limites do que é aceito usualmente como "real". Ainda que seja um tema sempre polêmico, essas acepções de "real" e de "sobrenatural", "extraordinário", estão na base da composição tanto dos contos de fadas, quanto na vida humana.

A seguinte reunião de falas do grupo evidencia que eles conseguem identificar uma estrutura em comum entre os contos de fadas: "Todos tem uma aventura" (J3); "Os protagonistas, eles passam juntos por todo um enredo" (J6); "Eu acho que, tipo, são histórias... que elas têm várias aventuras, acontecem vários conflitos, mas no final tudo se dá bem e os personagens eles amadurecem, ou fazem as pazes" (J7); "Geralmente conto de fadas tem isso né, mostra uma situação legal de início, e no desenvolvimento acontece algo ruim que o protagonista tenta consertar e no final acaba dando certo" (J6); "Algo que começa ruim, tem seus conflitos e termina feliz" (J6). Estrutura essa que, não por acaso, é a estrutura básica do gênero em que ele se materializada.

O conto de fadas, como o próprio nome já indica, organiza-se na forma discursiva do gênero narrativo conto. Jolles (1976, p. 181) nos diz que o conto só adotou verdadeiramente o sentido de forma literária determinada a partir do trabalho dos irmãos Grimm. Foram os contos de fadas desses autores que estabeleceram uma configuração específica para o gênero. Assim, nas suas palavras, "É costume atribuir-se a uma produção literária a qualidade de Conto sempre que ela concorde mais ou menos (para usar deliberadamente uma expressão vaga) com o que se pode encontrar nos contos de Grimm" (JOLLES, 1976, p. 182).

Coelho $(2000$, p. 71$)$ considera que o conto corresponde à estrutura mais simples do narrar, e explica que há apenas uma unidade dramática, ou motivo central 
desenvolvido através de situações breves, rigorosamente dependentes daquele motivo. Assim, Alcoforado (1986) explica que o desenvolvimento dessas histórias costuma seguir uma estrutura invariante:

os contos de encantamento ou de fadas, como são mais conhecidos, são aqueles que, partindo de uma indefinição espaço-temporal, falam de um herói que parte para uma aventura onde se depara com problemas de difícil solução e, só através da ajuda de elementos mágicos, pode superá-los, ser reconhecido como um herói e se casar com um descendente real (ALCOFORADO, 1986, p. 89).

Pouca variação tem também os personagens e situações familiares deles oriundos, o que nos leva ao próximo tópico.

Pullman (2014, p. 13) diz que o conto de fadas se vale de um repertório de figuras convencionais planas, de pouca vida interior, claras e óbvias em seus anseios. Assim, o grupo percebeu que o conto de fadas: "tem sempre a princesa que precisa ser salva por um príncipe" (J1); "tem sempre uma princesa que sofre nas mãos de uma madrasta" (J6); "tem sempre a ideia do mocinho, né, do herói, e do vilão" (J6), e que os personagens "são sempre a princesa, o rei, a madrasta, o príncipe e o casamento" (J3). O autor supracitado completa, ainda, que esses personagens "raramente têm nomes próprios. O mais frequente é que sejam nomeados por sua ocupação e sua posição social ou por uma particularidade da roupa: o moleiro, a princesa, o capitão, Pele de Urso, Chapeuzinho Vermelho" (PULLMAN, 2014, p. 13). São heróis ou vilões planos, sem volume, pois, "o conto está muito mais interessado no que acontece com eles, ou no que eles fazem acontecer, do que em sua individualidade" (PULLMAN, 2014, p. 15), ou seja, o conto está muito mais preocupado com a jornada até o "final feliz". 
Este tópico começa, então, com a transcrição da fala que precedeu uma profusão de reiterações dessa característica, a do final feliz: "Todo mundo tem aquela ideia de que conto de fadas é perfeito e vai ter final feliz" (J2). E, de fato, foi o que o grupo repetiu à exaustão: "Contos de fadas têm normalmente finais felizes" (J1); “... e tem que ter final feliz" (J6); "são histórias com final feliz" (J3); "Contos de fadas geralmente têm final feliz e ninguém morre" (J7); "Porque no final todo mundo que deveria se dar bem se dá bem... o casal principal fica junto, os vilões são derrotados..." (J3); "tudo dá certo no final, pras crianças começarem a acreditar nisso" (J7); "e no final tudo acaba bem" (J1).

O final feliz, para Bettelheim (2014), reassegura a esperança humana da resolução de todos os conflitos da vida, pois, nas suas palavras, "a história de fadas é sempre otimista, não importa o quão terrivelmente sérias possam ser algumas características desta última" (BETTELHEIM, 2014, p. 54), o que a diferenciaria substancialmente de outras narrativas.

Entretanto, a universalidade dessa característica é questionável, uma vez que finais trágicos são muito comuns em contos de fadas. Na versão de Perrault (2018) para "Chapeuzinho Vermelho", por exemplo, a história termina quando o Lobo Mau consegue finalmente comer a menina. Na versão dos Grimm (2012) de "O Flautista de Hamelim", o personagem-título, ao final da história, rapta todas as crianças do reino e nunca mais se ouve falar delas. Darnton (1988) explica que, na França do Antigo Regime, por exemplo, o que comovia nos contos era o próprio caráter da tragédia, e não o final feliz, que foi incorporado às histórias somente no início do século XIX, com suas reescrituras. Ainda assim, influenciado por essas versões, Andersen (2011) também encerrou muitos de seus contos de fadas de forma triste, como "A Pequena Sereia", que não consegue conquistar o seu amor e acaba virando espuma do mar. 
Interessante para a análise é, também, o fato do grupo não ter reconhecido os finais trágicos, que remetem diretamente aos textos clássicos de Perrault, Grimm e Andersen. A ideia do final feliz como elemento característico dos contos de fadas difundiu-se amplamente apenas no século XX, devido às adaptações cinematográficas de Walt Disney para essas histórias, visto que, como nos diz Parma (2009), "é próprio do discurso da Disney que o fim de seus filmes seja feliz, sintetizado pela frase 'e viveram felizes para sempre', para que ele agrade as crianças que lhe assistem" (PARMA, 2009, p. 515), visando à conquista do público infantil aos quais os filmes eram direcionados.

Entretanto, estudos como o de Cardoso (2006) apontam que a partir da década de 1990 foi possível notar uma mudança nesse panorama, com jovens e adultos começando a demonstrar interesse por esse tipo de produção. Assim, pouco a pouco, o que era restrito ao público infantil se tornou atualmente um entretenimento para todas as idades, ainda que no senso do grupo isso não esteja tão claro.

A ideia dos contos de fadas como algo infantil está, ainda, muito enraizada na concepção popular compartilhada pelo grupo, como as transcrições a seguir evidenciam: "Conto de fadas, pelo menos pra mim, remete a crianças" (J2); "conto de fadas normalmente é pra crianças" (J7); "a lembrança mais antiga que eu tenho [de contos de fadas] é de livros infantis" (J1); "contos de fadas vêm dos livrinhos infantis" (J5).

Tal concepção é produto do percurso histórico do gênero, que se consagrou como matéria para a infância fomentado por estudos como o de Bettelheim (2014), que ressalta o caráter positivo dessas histórias para as crianças, afirmando, por exemplo, que "como toda grande arte, os contos de fadas tanto encantam quanto instruem; seu talento especial é que fazem isso em termos que falam diretamente às crianças" (BETTELHEIM, 2014, p. 79). O psicanalista, como outros pensadores do tema, desenvolveu seu estudo 
todo em torno dessa concepção de que os contos de fadas ajudam especialmente a criança a entender a si e ao mundo, colocam ordem no caos interior que é a psique infantil, mas ignorou completamente algo que hoje os estudos do tema levam bastante em consideração: o contexto de origem dessas narrativas desconhecia a infância.

Darnton (1988) relata que, à época em que os contos de Perrault foram publicados, por exemplo, ninguém pensava nas crianças como criaturas inocentes em um estágio da vida distinto da juventude e da fase adulta por estilos especiais de vestimenta e comportamento. Assim, ainda que Corso e Corso (2006) concordem que os contos de fadas "fazem parte da educação desejável, assim como aprender a contar e se alfabetizar, e é impensável que uma criança cresça em um ambiente considerado estimulador sem ter entrado em contato jamais com Chapeuzinho Vermelho, João e Maria (...)" (CORSO; CORSO, 2006, p. 26 - grifo no original), Tatar (2003, p. 15) conta que uma das primeiras resenhas sobre os contos de Grimm, por exemplo, alertava que aquele tomo de histórias não era adequado para cair nas mãos de crianças, pois as histórias poderiam despertar sentimentos inconfortáveis às suas mentes e emoções em formação.

Assim, Colomer (2017, p. 154) garante que "a ideia de uma infância com interesses e necessidades formativas próprias levou, pois, à criação de livros especialmente dirigidos a este segmento de idade". É nesse sentido que Coelho (2000) afirma que os contos de fadas, "antes de se perpetuarem como literatura infantil, foram literatura popular" (COELHO, 2000, p. 41 - grifo no original). Mas, como veremos a seguir, não atravessaram essas transformações de forma incólume. O que o grupo destaca e que sistematizamos de suas falas a seguir é o fato de que valores hegemônicos da sociedade estão impressos nessas histórias como parte do processo de naturalização dos mesmos. 
Importante começar este tópico salientando que essa percepção foi levantada, primeiramente, por uma participante do gênero feminino, quando disse: "Tem sempre a princesa que precisa ser salva por um príncipe e ela tá sempre indefesa e sempre precisa de ajuda e ela agradece casando com esse príncipe" (J1). Após isso, seguiram-se outros comentários, em momentos diversos, como: "Nunca falta o Príncipe Encantado delas... que na historinha era tudo que elas sempre sonharam pra elas" (J4); "A gente sempre vê a princesa presa sem poder sair do castelo ou limpando a casa pros outros, cuidando dos outros..." (J7); "A Branca de Neve... só ela limpava a casa em que oito pessoas moravam!" (J1).

Tal percepção vai ao encontro de Sky (2002), quando esta afirma que a fonte dos contos de fadas "pode muito bem estar na tradição folclórica oral, mas ao ser escrita por escritores homens, em sua maioria, de classe média ou alta, seus haveres mudaram junto com o público pretendido" (SKY, 2002, p. 370 - tradução do autor). O estudioso ainda verifica que os contos de Grimm, por exemplo, demonstram uma notável tendência para a naturalização do patriarcado: eles se concentram em validar as mulheres como submissas ao poder dos homens.

Tal constatação também é feita acerca dos contos de Perrault, por Mendes (2000, p. 126), quando esta aponta que nas entrelinhas dos textos publicados pelo autor o que transparecem são preconceitos de uma sociedade extremamente machista. Enquanto os personagens masculinos são sempre valentes e poderosos, as personagens femininas são sempre elevadas pelas virtudes de sua beleza e fragilidade. Como a autora diz, "se a mulher não fosse bela, não seria feminina. Era o primeiro dom com que se preocupavam as fadas, e era a razão da interferência do herói. O príncipe só salvava a jovem ameaçada 
ou atingida pelo mal depois de vê-la e encantar-se com sua infinita beleza" (MENDES, 2000, p. 130).

Não são imotivadas, então, as afirmações de Haase (1993) quanto ao fato de que os valores vistos nos contos de fadas "como atemporais e comuns a todos, venham a ser os da sociedade patriarcal e autoritária" (HAASE, 1993, p. 392 - tradução do autor) em que ele e todos nós crescemos e a qual essas histórias ajudam a manter, segundo Zipes (1999, p. 338 - tradução do autor), "reforçando a ordem simbólica patriarcal baseada em uma rígida noção de sexualidade e gênero" apresentadas nas histórias.

Nanda (2014) aprofunda mais na questão e diz que

os contos de fadas incorporam as formas pelas quais as sociedades tentaram silenciar e oprimir as mulheres tornando-as passivas. Grande parte da literatura de contos de fadas reforça a ideia de que mulheres devem ser esposas e mães, submissas e abnegadas. Boas mulheres, nessas histórias, devem ficar em silêncio, não ter ambição, serem bonitas e ansiosas para casar (NANDA, 2014, p. 248).

É possível concordar, então, com Desczc (2002, p. 85), quando diz que os contos de fadas vêm sendo usados como um poderoso veículo afirmador de antigos valores que embalam o público em conformidade e passividade com o status-quo da nossa sociedade. Tal característica está intimamente ligada à ideia de conto de fadas como uma história com mensagem moral, conforme o grupo verbalizou: "Ah, eu acho que conto de fadas é uma historinha que no final vai ter uma moralzinha" (J6); "Acho que é conto de fadas pela moral" (J3); "tem que ter uma moral, conto de fadas" (J7).

Entretanto, Coelho (2000, p. 167) demonstra que o gênero literário tradicionalmente associado à transmissão de moralidades é o das fábulas. Essas histórias, 
que ganharam o mundo por La Fontaine e Esopo, a partir dos gregos, atravessaram os séculos sob estável perenidade tal qual os contos de fadas. Mendes (2000) conta que no prefácio da coletânea Contos de Mamãe Gansa, "Perrault compara suas histórias às famosas fábulas milesianas, tão apreciadas na Grécia e em Roma, ressalvando que são superiores às da Antiguidade, pois contêm uma moral nobre, que o paganismo não podia transmitir" (MENDES, 2000, p. 49).

Zipes (2006a, p. 30) fala que Perrault publicou seus contos de fadas, em maior parte, mais para expressar sua visão de como as pessoas deveriam desempenhar seus papeis na sociedade na época do que para propagar valores religiosos. Mendes (2000) evoca palavras do próprio Perrault em prefácio para afirmar que “Os contos mostrarão ‘a vantagem de ser honesto, paciente, previdente, trabalhador, obediente...' (ibidem, p. 183), exatamente as qualidades que o rei esperava de seus súditos, os maridos, de suas esposas e os pais, de seus filhos" (MENDES, 2000, p. 51), como evidenciam declarações dos participantes: "é que eu acho que nenhum conto de fadas foi escrito em vão, né, eles tinham um objetivo" (J6); "são feitas pra nos alertar, tipo... não pode mentir se não cresce o nariz" (J7); "é que eu acho que nenhum conto de fadas foi escrito em vão, né, eles tinham um objetivo, por exemplo, 'moças sejam princesas, por favor, esperem seus príncipes', na verdade era isso" (J6).

Factualmente, dentre os três nomes mais reconhecidos no ocidente atualmente como autores de contos de fadas, Perrault foi o único que redigiu morais ao final das histórias que publicou. Cada narrativa presente em Contos da Mamãe Gansa apresenta uma ou duas pequenas rimas compostas pelo próprio autor, que veiculam algum ensinamento moralizante extraído da história. Talvez por isso os participantes do grupo 
também tenham dito: "as histórias mostram o que é errado" (J2); "são histórias que a gente aprende algumas coisas boas sobre a vida" (J7).

Com relação às rimas mencionadas, sabe-se que elas não eram entoadas em suas versões orais. Em edições atuais de contos de Perrault, a menos que se tratem de traduções diretas do original, a moral também não está explicitada. Nada do tipo é encontrado nos contos de Grimm ou Andersen, ainda que preceitos morais estejam presentes intrinsecamente. Nesses contos deles, se o objetivo era ensinar algo, a história falava por si mesma.

Encaminhando-nos para o final da análise, chega o momento de evidenciar que nem só de conformidades moveram-se as ideias dentro do grupo. Os participantes também ofereceram percepções acerca do gênero contos de fadas que não se configuravam como um comum acordo entre todos ou destoavam do que os estudos críticos acerca dessas narrativas postulam. Destacamos quatro contrassensos-chave dentre esses desacordos, levando como critério para tal a recorrência deles nos encontros.

O primeiro contrassenso baseia-se na ideia de que os contos de fadas são histórias românticas ou de amor: "É daí que a gente tira essa ideia do amor perfeito, do 'príncipe encantado', que vai arrumar alguém e ser feliz pro resto da vida, que a pessoa não vai ter defeitos, e que vai casar e ser feliz pra sempre e viver o 'seu' conto de fadas" (J6). Apesar da ênfase dada em grande parte dos contos de fadas, tanto pelos leitores quanto pela mídia, à questão do amor romântico entre a protagonista e o seu "príncipe encantado", o que torna a ideia expressa pela fala transcrita um erro comum é que essas histórias não são, efetivamente, sobre a busca do amor verdadeiro. Nenhum estudioso lega a esse tema o cerne dos contos de fadas. E um número tão pequeno quanto, se em relação ao 
montante de sua totalidade, termina com um casamento. Essas histórias são muito mais sobre a resolução e superação de problemas e conflitos, como Corso e Corso (2006) postulam, por exemplo, dos quais pode emergir como consequência ou recompensa um episódio de amor romântico, do que efetivamente sobre ele.

Outra ideia comumente errônea sobre contos de fadas é acreditar, influenciado pelo nome, de que são histórias que têm fadas: "Eu tô pensando em histórias que têm fadas" (J7). As fadas, apesar de aparecerem em alguns dos contos, não são personagens tão recorrentes nessas histórias quanto o nome do gênero pode nos dar a entender. Essas mulheres dotadas de poderes, às vezes retratadas como alados seres diminutos, às vezes muito semelhantes à figura das feiticeiras, fazem participações bastante pontuais, em muito poucas delas, tanto amaldiçoando os protagonistas, quanto os abençoando.

Muito devido à popularização dessas histórias através do cinema de animação, é comum, também, pensar que contos de fadas são "histórias da Disney": "Esse não deve ser conto de fadas porque não é da Disney" (J3), foi dito em certo momento e repetido em vários outros. Tampouco a Disney inventou os contos de fadas, mas sim se apropriou deliberadamente deles. Dessa forma, nem toda narrativa Disney é uma adaptação de algum conto de fadas e nem todo conto de fadas tem uma adaptação Disney. Alguns dos filmes mais famosos dos estúdios em sua época de animações 2D, como Mulan e Pocahontas, sequer são contos de fadas. Alguns contos de fadas bastante populares, como Chapeuzinho Vermelho ou João e Maria, sequer têm adaptações Disney.

O último contrassenso recorrente no grupo foi a ideia de que contos de fadas são todas as narrativas com elementos que não existem no mundo em que vivemos: "Tem também Alice, com um coelho que sabe ver as horas, Pinóquio com um boneco que fala $e$ O Mágico de Oz que um furacão leva a Doroty pra outra terra" (J1). 
Não é possível encerrar também o gênero apenas nesse espectro do que lida com "coisas que não existem no nosso mundo", pois vários outros gêneros de histórias narram lugares, personagens e situações que não pertencem ao cotidiano mundano que nos cerca, averiguável aos nossos olhos. É possível pensar, para além dos contos de fadas, a ficção científica, o horror, a alta fantasia, como um pequeno apanhado de gêneros que pautam-se, também, em quebrar com a realidade. Bem como Alice, Peter Pan e O mágico de $\mathrm{Oz}$, como citados, possuem outra extensão textual que não a do gênero conto, pertencem a outro movimento feito pela literatura, em outra época histórica e, apesar de claramente influenciados pelos contos de fadas, não se enquadram na mesma categoria que eles.

\section{Considerações}

Quando Sale (1977, p. 372) diz que "conto de fadas" é apenas uma convenção para designar certo tipo de história, ele refere-se justamente à imprecisão teórica do conceito, difícil de ser fechado em si. Entretanto, o que esta pesquisa revela é que ao largo dessa dificuldade técnica dos estudos formais, os leitores, a partir do seu contato empírico com os textos literários do gênero, criam seus próprios mecanismos para reconhecê-los e enquadrá-los dentro de um conceito que os designe. Assim, ainda que os distanciamentos elencados não sirvam como bons critérios de diferenciação, as diversas aproximações estabelecidas ajudam a agrupar características dessas narrativas em uma (re)leitura potencial nessa busca de um conceito para o gênero literário contos de fadas.

Com base, então, nas discussões empreendidas foi possível determinar que a releitura feita do conceito de conto de fadas, pelo grupo pesquisado, delibera que as 
histórias desse gênero literário são, para eles, narrativas ligeiramente familiares aos nossos olhos e ouvidos, geralmente dirigidas às crianças, que devem conter situações extraordinárias, mas ir além, obedecendo a uma forma básica que termina em um final feliz, recompensador, que sempre expressa um ensinamento moral, ainda que este reproduza algum valor ou concepção de mundo tradicional.

\section{Referências}

ALCOFORADO, Doralice Fernandes Xavier. O conto popular. Revista Sitiembus, Feira de Santana, BA, n. 5, v. 3, p. 87-99, 1986.

ANDERSEN, Hans Christian. Contos de Hans Christian Andersen traduzidos do dinamarquês. Tradução Silva Duarte. São Paulo: Paulinas, 2011.

BASTOS, Glória. Fantasia e realidade na literatura para crianças. Discursos. Portugal, n. 8, p. 113-126, 1994.

BETTELHEIM, Bruno. A psicanálise dos contos de fadas. Tradução Arlene Caetano. São Paulo: Paz e Terra, 2014.

CARDOSO, Rodrigo da Silva. Quem disse que filme de animação é coisa só de criança? 2006. 93 f. TCC. (Curso de Bacharel em Comunicação Social com habilitação em Publicidade e Propaganda) - Centro Universitário de Brasília - UniCEUB, Brasília, 2006.

COELHO, Nelly Novaes. Literatura infantil: teoria - análise - didática. São Paulo: Moderna, 2000.

COLOMER, Teresa. Introdução à literatura infantil e juvenil atual. São Paulo: Global, 2017.

CORSO, Diana Lichtenstein; CORSO, Mário. Fadas no divã: psicanálise nas histórias infantis. Porto Alegre: Artmed, 2006.

DARNTON, Robert. O grande massacre dos gatos, e outros episódios da história cultural francesa. Tradução Sonia Coutinho. Rio de Janeiro: Graal, 1988.

DESCZC, Justyna. Beyond the Disney spell, or escape into Pantoland. Folklore, UK, v 113, n. 1, p. 83-91, 2002. 
GATTI, Bernadete Angelina. Grupo focal na pesquisa em ciências sociais e humanas. Brasília: Liber Livro Editora, 2012.

GRIMM, Jacob e Whilhelm. Contos maravilhosos infantis e domésticos. São Paulo: Cosac Naify, 2012.

HAASE, Donald. Yours, mine, or ours? Perrault, the brothers Grimm, and the Ownership of fairy tales. Merveilles \& contes, Detroit, v. 7, n. 2, p. 383-402, dez. 1993.

The greenwood encyclopedia of folktales and fairytales. Westport: Greenwood Press, 2008.

JOLLES, André. Formas simples. São Paulo: Cultrix, 1976.

MENDES, Mariza B. T. Em busca dos contos perdidos. O significado das funções femininas nos contos de Perrault. São Paulo: Editora Unesp/Imprensa Oficial do Estado de São Paulo, 2000.

NANDA, Silima. The portrayal of women in the fairy tales. The International Journal of Social Sciences and Humanities Invention, Nova Delhi, v, 1, n. 4, p. 246-250, 2014.

PARMA, Alan Febraio. A homogeneização de gêneros literários nos filmes de Walt Disney. Revista Língua, Literatura e Ensino, v. 4, 2009, p. 506-516.

PERRAULT, Charles. Contos da mamãe gansa ou histórias do tempo antigo. Tradução Leonardo Fróes. São Paulo: SESI-SP, 2018.

PROPP, Vladimir. Morfologia do conto maravilhoso. Tradução Jasna Paravich Sarhan. 2. ed. Rio de Janeiro: Forense Universitária, 2006.

PULLMAN, Philip. Contos de Grimm: para todas as idades. Tradução José Rubens Siqueira. Rio de Janeiro: Objetiva, 2014.

SALE, Roger. Fairy tales. The Hudson Review. Princeton, v. 30, n. 3, p. 372 - 394, 1977.

SKY, Janette. Myths of innocence and imagination: the case of the fairy tale. Literature \& Teology. Oxford, v. 16, n. 4, p. $363-376,2002$.

ZIPES, Jack. Break the Disney spell. The classic fairy tales: texts, criticism, ed. Maria Tatar. New York: WW Norton \& Company, 1999.

Fairy tales and the art of subversion: the classical genre for children and the process of civilization. New York: Routledge, 2006. 
Paulo Ailton Ferreira da Rosa Junior

Recebido em 5 de abril de 2019.

Aceite em 16 de maio de 2019. 